\title{
VIRTUAL VERSUS CONVENTIONAL COLONOSCOPY SYSTEMATIC REVIEW
}

\author{
Altin Jusufati ${ }^{*}$, Krenar Preza ${ }^{2}$ \\ ${ }^{1 *}$ University Hospital Centre "Mother Teresa", Tirana, Albania; \\ ${ }^{2}$ Continetal Hospital, Tirana, Albania;
}

"Corresponding author Altin Jusufati, e-mail: altin_md@yahoo.com;

Received October 2018; Accepted January 2019; Published February 2020;

DOI: https://doi.org/10.31407/ijees10.128

\begin{abstract}
Virtual colonoscopy (CTC) is considered investigational or experimental, for patients with inflammatory bowel disease, including Crohn's, ulcerative colitis, or diverticulitis and cancerous lesions. CTC has several advantages over colonoscopy. It is more comfortable for the patient, does not require sedation (so there is no anesthetic risk like in colonoscopy), and does not disqualify any patients for certain medical reasons, as colonoscopy sometimes does. CTC also requires less time to complete and return to normal activities than colonoscopy, it carries no risk of surgical complications. CT colonography is highly sensitive for colorectal cancer, especially when both cathartic and tagging agents are combined in the bowel preparation. Given the relatively low prevalence of colorectal cancer, primary CT colonography is more suitable than conventional colonography for initial investigation of suspected colorectal cancer, assuming reasonable specificity.
\end{abstract}

Key words: Colon, computed tomography (CT), multidetector CT, colonoscopy 